\title{
Transforming Degraded Smallholder Farmland into Multi-Functional Land Use Systems: A Case Study From Tanzania ${ }^{\dagger}$
}

\author{
Anika Reetsch 1,*, Gerald Kapp ${ }^{2}$, Karl-Heinz Feger ${ }^{3}$, Kai Schwärzel ${ }^{4}$ and Christina Dornack 5 \\ 1 UNU-FLORES, Technische Universität Dresden, 01067 Dresden, Germany \\ 2 Institute of International Forestry, Forest Products, Technische Universität Dresden, 01069 Dresden, \\ Germany; gerald.kapp@tu-dresden.de \\ 3 Institute of Soil Science, Site Ecology, Technische Universität Dresden, 01069 Dresden, Germany; karl- \\ heinz.feger@tu-dresden.de \\ 4 Institute for Integrated Management of Material Fluxes and Resources, United Nations University, Tokyo \\ 150-8925, Japan; schwaerzel@unu.edu \\ 5 Institute of Waste Management, Circular Economy, Technische Universität, 01069 Dresden, Germany; \\ christina.dornack@tu-dresden.de \\ * Correspondence: reetsch@unu.edu \\ † Presented at TERRAenVISION 2019, Barcelona, 2-7 September, 2019.
}

Published: 12 November 2019

\begin{abstract}
In our research, we have studied smallholder farmers in degraded farming systems in Northwest Tanzania and have compared them with farm households who were trained in sustainable land management by a local Farmer Field School. Both groups of farmers were affected by severe environmental degradation and poor soil fertility, but trained farmers have transformed degraded farmland into fertile, multi-functional land use systems. In this presentation, we discuss the successes and failures of both groups of farmers and draw conclusions towards restoring degraded land use systems. Farmers without training cannot restore degraded farmland with traditional agricultural management alone and fail to produce enough food, fodder, biofuel, and timber to support the whole family. The reasons for their failure are manifold and include environmental and socio-economic dimensions, e.g., poor management of soils and farm waste, lacking adaptation to climate change, traditional gender roles, and the loss of knowledge and labour in HIV/AIDS-affected households. In comparison, trained farmers change nutrient management by using advanced composting techniques. They also cultivate a greater variety of crops and trees, introduce organic pesticide management, ease manure collection, construct vegetable gardens that are watered by drip irrigation in the dry season, change gender roles and communication structures. The main differences between both groups of farmers occur in food security, health status, education level, marketing, income generation, prosperity, and gender-related responsibilities. However, the full potential of organic farm waste being used as soil fertiliser is not exhausted, as human excreta is not integrated into nutrient management. Farm households who are most vulnerable to food security, e.g., female-headed and HIV/AIDS-affected households, need to get support in strengthening their socio-economic base before transforming the farm management. In conclusion, local Farmer Field Schools significantly contribute to restoring land degradation. To transform smallholder agriculture in Tanzania, a joint partnership with local governmental organisations could help farmers to escape poverty and become food secure (SDG 1 and SDG 2). Similar approaches could support smallholder farmers in East Africa, where they contribute to three-fourth of the agricultural production.
\end{abstract}

Keywords: land restoration; multifunctionality; agricultural intensification; smallholder farmers; tropical highlands 
(C) 2019 by the authors. Licensee MDPI, Basel, Switzerland. This article is an open access article distributed under the terms and conditions of the Creative Commons Attribution (CC BY) license (http://creativecommons.org/licenses/by/4.0/). 